\title{
NARRATIVAS SOBRE O USO DE TECNOLOGIAS SOCIAIS IMPLANTADAS NA COMUNIDADE RIBEIRINHA DO CANAL FURO GRANDE, ILHA DAS ONÇAS, BARCARENA (PARÁ, BRASIL).
}

\section{NARRATIVES ON THE USE OF SOCIAL TECHNOLOGIES IMPLEMENTED IN THE RIVERSIDE COMMUNITY OF FURO GRANDE CANAL, ILHA DAS ONÇAS, BARCARENA (PARÁ, BRAZIL).}

\author{
Yuri Antônio da Silva Rocha ${ }^{(1)}$ \\ Graduando em Engenharia Ambiental e Energias Renováveis. Técnico em Edificações. \\ Danúbia Leão de Freitas ${ }^{(2)}$ \\ Graduanda em Engenharia Ambiental e Energias Renováveis. \\ Ranielly Souza Monteiro da Silva ${ }^{(3)}$ \\ Graduanda em Engenharia Ambiental e Energias Renováveis. \\ Vania Neu ${ }^{(4)}$ \\ Bióloga, Mestre em Ecologia de Agroecossistemas e Doutora em Ecologia Aplicada.
}

E-mail ${ }^{(1)}$ : pes.yuriantonio@gmail.com

\section{RESUMO}

A falta de água potável e de saneamento básico é um dos problemas mais comuns na Amazônia. Perante essa realidade, em 2012 foi iniciado junto à comunidade ribeirinha do canal Furo Grande, Ilha das Onças (Barcarena, Pará) o desenvolvimento de duas tecnologias sociais, cujo objetivo foi fornecer água potável para o consumo humano e saneamento básico. O presente trabalho objetivou coletar a percepção da comunidade ribeirinha beneficiada com duas tecnologias sociais (TS): os Sistemas de Captação de Água de Chuva (SCAC) e os Banheiros Ecológicos Ribeirinhos (BER). O levantamento de dados foi realizado por meio de entrevistas gravadas com os ribeirinhos beneficiários pelo projeto. Ao longo dos nove anos de trabalho junto à comunidade, constatou-se a percepção de que as tecnologias são eficientes para regiões na qual foram implantadas, garantindo o saneamento básico seguro, a provisão de água potável, trazendo ainda conforto, economia, qualidade de vida e melhorias ambientais.

\section{ABSTRACT}

The lack of potable water and basic sanitation is one of the most common problems in the Amazon. In view of this reality, in 2012 the development of two social technologies, whose objective was to provide potable water for human consumption and basic sanitation, began with the riverside community of the Furo Grande channel, Ilha das Onças (Barcarena, Pará). This study aimed to collect the perception of the riverside community benefiting from two social technologies (TS): the Rainwater Collection Systems (SCAC) and the Riverside Ecological Bathrooms (BER). The data survey was carried out through recorded interviews with the riverside beneficiaries of the project. Over the nine years of work with the community, there was a perception that the technologies are efficient for the regions in which they were implemented, ensuring safe basic sanitation, the provision of potable water, bringing comfort, economy, quality of life and environmental improvements.
\end{abstract}

Palavras-chave: Tecnologias Sociais. Água potável. Saneamento básico. Amazônia.

Key words: Social Technologies. Potable water. Sanitation. Amazon.

\section{INTRODUÇÃO}

A dificuldade de acesso à água potável e ao saneamento básico em comunidades ribeirinhas ainda é um problema recorrente na região Amazônica. Por mais que a água seja um recurso abundante nesta região, apenas uma pequena fração é potável e está disponível para consumo humano (NEU; DOS SANTOS; MEYER, 2016) e, embora a ONU reconheça que o acesso à água potável é um direito 

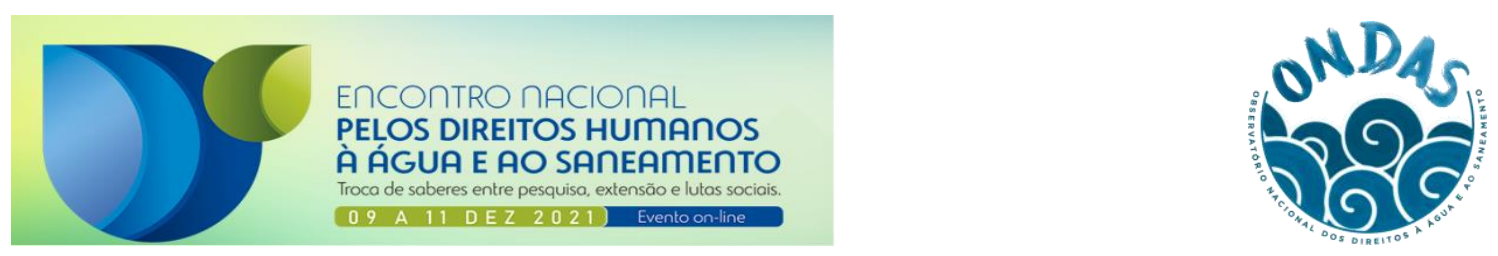

universal, até hoje, a garantia desse direito ainda não foi claramente definido (NEU et al., 2018).

No meio rural, assim como em muitas áreas urbanas na Amazônia, a ausência de saneamento básico faz com que fezes e urinas sejam conduzidas ou despejadas de forma in natura nos rios, ou no solo, contaminando os sistemas aquáticos (NEU; DOS SANTOS; MEYER, 2016). Os rios são, para muitos, a principal fonte de água utilizada para o consumo humano, o que gera um cenário frequente de doenças de veiculação hídrica e perda de vidas humanas devido à ausência de serviços básicos. Logo, políticas públicas que forneçam melhores condições de vida, sem que alterem seus modos de vida tradicionais, são necessariamente urgentes nesta região.

Perante as dificuldades vividas pelas comunidades rurais no estado do Pará, o Laboratório de Hidrobiogeoquímica, da Universidade Federal Rural da Amazônia, desenvolveu junto à comunidade ribeirinha do canal Furo Grande duas tecnologias sociais (TS). A primeira delas foi para suprir o acesso à água potável, por meio do Sistema de Captação da Água da Chuva (SCAC), seguido do Banheiro Ecológico Ribeirinho (BER). A parceria resultou na implantação de quinze sistemas, junto às residências das famílias na Ilha das Onças. Logo, este trabalho objetivou avaliar a percepção da comunidade ribeirinha do canal Furo Grande através de narrativas dos moradores beneficiados pelas tecnologias.

\section{METODOLOGIA}

\section{1. Área de Estudo}

Os Banheiros Ecológicos Ribeirinhos (BER) e os Sistemas de Captação da água da Chuva (SCAC) foram implantados no Canal Furo Grande, Ilha das Onças (Barcarena/PA) (Figura 1), em quinze residências ribeirinhas. A Ilha das Onças, drenada por diversos rios e canais, possui uma área de 96 $\mathrm{km}^{2}$ e está localizada no Estuário Guajarino, à margem esquerda da Baía do Guajará (NEU et al., 2018).

Figura 1 - Localização do Canal Furo Grande na Ilha das Onças, Barcarena, Pará, Brasil.

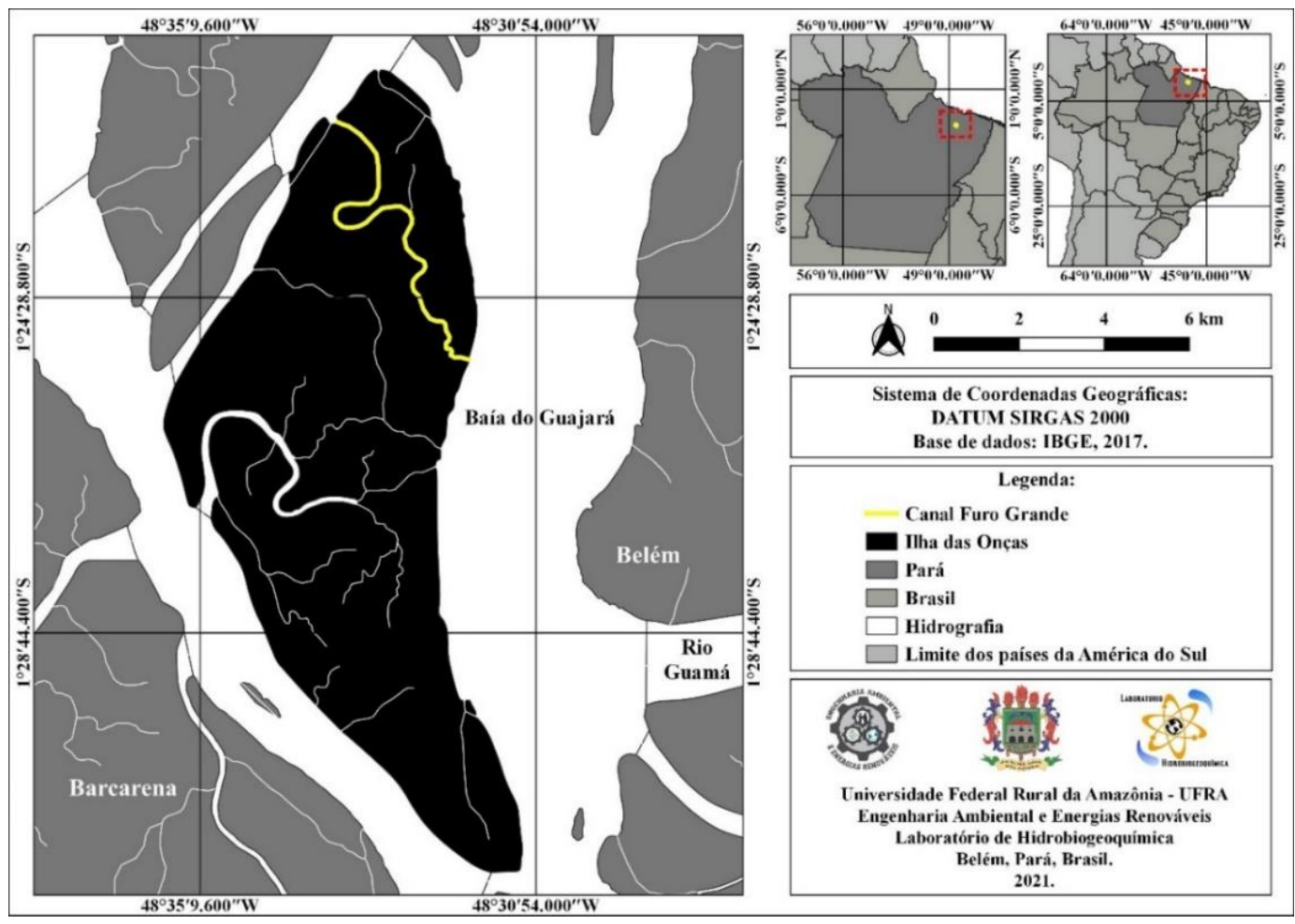

Fonte: Os autores, 2021. 


\section{Levantamento de dados}

As entrevistas foram realizadas junto aos moradores beneficiados pelas tecnologias sociais no ano de 2019. Os relatos da comunidade foram gravados com o uso de celulares após o consentimento de cada entrevistado, preservando a identidade de cada um, sem quaisquer identificações nominais das pessoas. Para obter o relato da comunidade foram realizadas perguntas abertas, pelas quais os entrevistados ficaram livres para fazer apontamentos acerca das tecnologias sociais implantadas em suas residências.

\section{RESULTADOS E DISCUSSÃO}

\subsection{Mudança com a implantação do Banheiro Ecológico Ribeirinho (BER)}

Dentre os principais benefícios relatados pelos entrevistados, destacou-se a eliminação do mau cheiro que os banheiros tradicionais (Figura 2A), nos quais havia exposição de fezes e urina, trazia próximo às residências. Mesmo com a higiene diária das "casinhas" o odor forte não era eliminado.

"[...] porque eu vejo que não tem mau cheiro facilita, às vezes a gente tinha o trabalho de tá lavando todo dia. Com ele é bem mais prático porque não tem o mau cheiro" (ENTREVISTADA 01, 2019).

O BER (Figura 2B) tem proporcionado o fortalecimento dos valores associados à autoestima dos moradores, influenciando nas relações entre indivíduos da comunidade e seus visitantes. Dentro desse contexto, o sentimento de bem-estar individual e coletivo é percebido pelo prazer em receber pessoas e por lhes oferecer um banheiro, caso necessário. Nos banheiros ribeirinhos tradicionais, os dejetos humanos lançados diretamente no solo ou água, sem tratamento, liberavam fortes odores, trazendo um desconforto, ou mesmo uma certa "timidez" em receber visitas nas residências.

"[...] melhorou porque tive um banheiro; o pessoal vem, gostam [...], acham interessante. Quando funciona certinho é bacana, com serragem, sem cheiro nenhum!" (ENTREVISTADA 02, 2019).

"Para nós aqui, eu, meu esposo e minha família, isso melhorou em termo até mesmo de visita [...]; a gente teve mais oportunidade de trazer gente aqui na nossa casa [...]" (ENTREVISTADA 03, 2019).

Figura 2 - Banheiro tradicional ribeirinho (A); Banheiro ecológico ribeirinho (BER) (B).

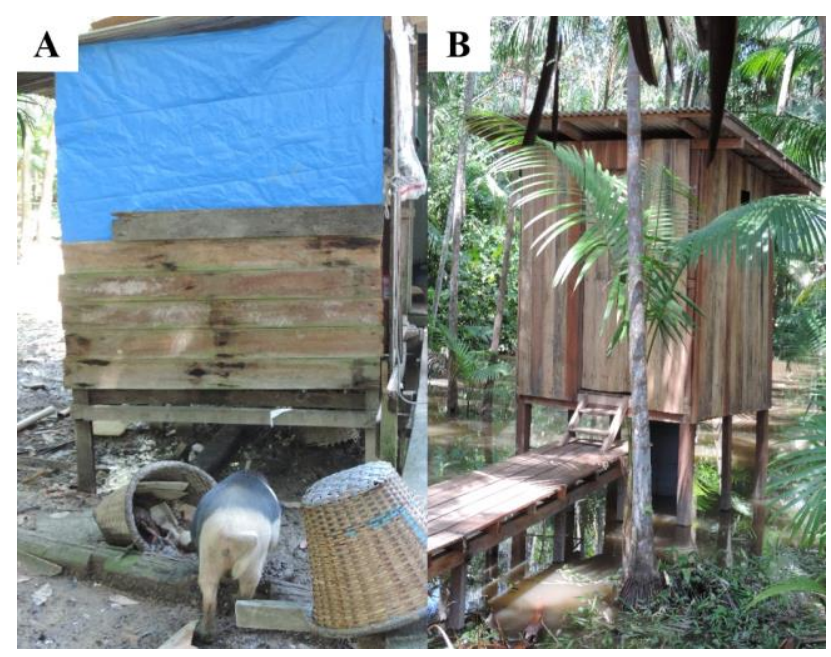

Fonte: Os autores, 2018. 
A segurança é outro fator apontado. Devido à eliminação do odor, o BER pode ser construído próximo às residências, em muitos casos, acoplado à casa, como um cômodo à mais. Dessa forma, o uso do banheiro, especialmente a noite, se tornou um ato mais tranquilo, por evitar encontros com animais peçonhentos que são frequentemente encontrados durante a noite. Acidentes com animais peçonhentos ocorrem com muita frequência nas regiões tropicais e neotropicais (BARRAVIEIRA, 1991), predominantes nos meses quentes e chuvosos, sendo mais frequente nas áreas rurais (OLIVEIRA et al., 2013). Waldez e Vogt (2009) apontaram que a maioria dos acidentes, mais de $80 \%$, com cobras são registrados durante o período de cheia dos rios, entre os meses de dezembro e junho em ambiente de terra-firme. Em muitos casos os acidentes resultam em óbito da vítima devido às grandes distâncias até os centros de saúde (OLIVEIRA et al., 2013), ou até mesmo devido à ausência de um meio de transporte.

"[...] tem menos risco de ir ao banheiro, porque muitas das vezes tem cobra, tem sapo, e aqui não [...]; a gente pode entrar livremente no banheiro, sem nenhum medo, sem nenhuma dificuldade e isso, aqui, pra mim, foi uma melhoria muito boa mesmo. Não tenho do que me queixar desses banheiros [...]" (ENTREVISTADA 03, 2019).

“[...] o banheiro foi uma melhoria muito boa, antes eu tinha que sair à noite pra ir no banheiro, me arriscando, porque as vezes tem bicho; agora não, tenho um banheiro dentro do теи quarto - era tudo que eu queria!” (ENTREVISTADA 05, 2019).

Além dos benefícios estéticos, de higiene, conforto e segurança, os benefícios se estenderam também à questão ambiental. Diferente dos banheiros convencionais, que contribuem para a proliferação de vetores, zoonoses e contaminação dos corpos hídricos, o banheiro ecológico promove o tratamento dos dejetos por meio da compostagem, devolvendo ao meio ambiente, um fertilizante seguro e rico em nutrientes.

"A gente ficou muito bem. Por exemplo, (reduziu) a poluição do rio, da terra, pra mim foi bom [...]" (ENTREVISTADA 04, 2019).

\subsection{Utilização do Sistema de Captação da Água da Chuva - SCAC}

A comunidade do Furo Grande não apresenta uma alternativa de acesso à água potável. Segundo relatos da comunidade à prefeitura municipal de Barcarena, fornece 40 litros de água por mês. Essa água chega em tambores não lacrados e, portanto, não se sabe a procedência e a qualidade da água fornecida, além de ser insuficiente para atender às necessidades das famílias (NEU et al., 2018). À vista disso, o primeiro aspecto observado no discurso dos moradores foi a independência e o empoderamento pela disponibilidade de água potável em quantidade e qualidade.

“A gente ficava muito preocupado com a questão da água, porque, assim... teve um período que o rapaz não veio trazer a água e a gente ficou sem água mesmo e com isso aqui [SCAC], a gente dificilmente fica sem água. Então, é uma preocupação que a gente não tem mais. Ano passado teve um período de três meses sem chover, minha caixa era menor, de 1000 litros e a gente ficou sem água; agora a caixa é maior e não ficamos sem água; não tenho mais esse problema e ainda dou água para os vizinhos quando eles querem" (ENTREVISTADA 06, 2019).

"Hoje eu me sinto bem satisfeita. No outro tempo [sem água de chuva], a dificuldade de água era tudo controlado, e era só para beber mesmo. Prefeito mandava aqueles dois carotezinhos uma vez no mês para a gente beber; quando não, tinha que 
comprar. Eu colocava minhas vasilhinhas lá na biqueira para aparar [a água da chuva]. Hoje não né, já tenho água em abundância" (ENTREVISTADA 05, 2019).

Outra mudança enfatizada pelos entrevistados foi a melhoria na saúde das famílias. Em levantamento realizado com a comunidade no ano de 2014, a comunidade relatava a frequência de doenças diarreicas, alergias, problemas de pele e estomacais antes da implantação dos Sistemas de Abastecimento de Água de Chuva (Figura 3A e 3B). A ingestão de água contaminada do rio ou mesmo a adição de químicos para tentar melhorar a qualidade da água acabava por trazer inúmeras enfermidades. Hoje com acesso à água da chuva, limpa e potável (Figura 3B) a comunidade relata que as doenças diminuíram, e consequentemente as idas ao médico e também gastos com medicamentos. $\mathrm{O}$ acesso à água segura e de qualidade promove bem-estar e disposição ao trabalho. Facilita especialmente a vida das mulheres, as quais estão incumbidas com as tarefas do lar e consequentemente com a busca da água. Além da água do rio contaminada e barrenta, a dificuldade de acesso até o rio e o carregamento de baldes de água era um desgaste físico diário necessário para o abastecimento da casa, tanto para o consumo humano, quanto para as demais atividades do lar. Hoje com água de chuva, além do consumo humano, ela também vem sendo utilizada para várias atividades como a limpeza da casa e das roupas.

Figura 3 - Sistema de Captação de Água de Chuva (A); Água da chuva armazenada na caixa d'água do SCAC (B).

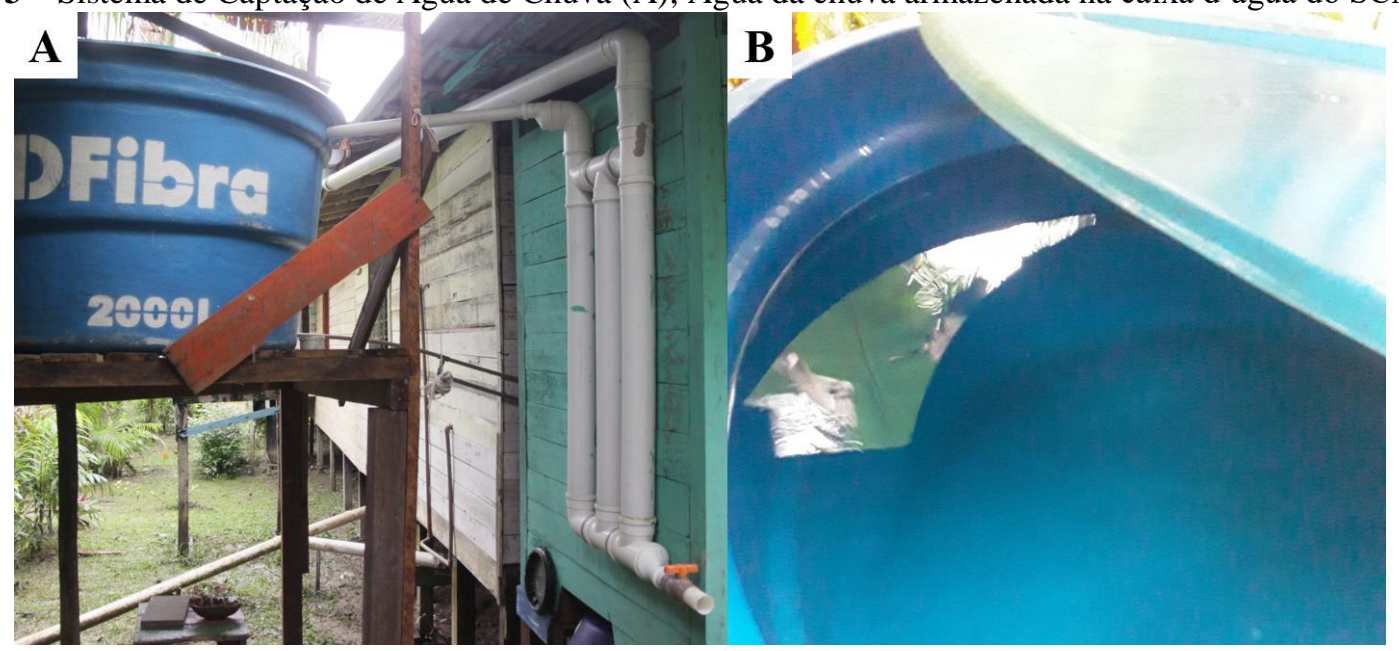

Fonte: Os autores, 2019 e 2020.

"Mudou muita coisa. Mudou a questão de ter água melhor para se beber, porque a do rio, você sabe, né... acaba sendo contaminada, porque as pessoas acabam fazendo muitas coisas que não deviam fazer. E a questão da saúde, questão da roupa, questão de alimento para cozinhar, você tem água para lavar roupa branca, você tem água para beber" (ENTREVISTADA 07, 2019).

"Eu tô feliz, na maneira que a gente não veio a adoecer mais, a minha filha, faz um ano que não vai ao médico... graças à Deus, não tem problema nenhum. Queixa de diarreia, coceira, graças à Deus, não existe mais. Melhorou muito porque a gente vivia com problema de coceira, a gente depois que começou a usar [da chuva], melhorou muito a vida da gente, então a gente economizou com remédio, com sofrimento, que eu acho que é a pior coisa, o sofrimento com febre, gripe e diarreia. Eu dou, falo - olha, podem pegar, água boa, filtrada, uma coisa boa que vem da natureza - [...]. Então pra mim é uma coisa boa. Ontem eu falei pro pessoal de Belém que tava aqui - olha é água boa de cisterna, água filtrada, não tenho o que me queixar dela e eu acho que não vai fazer mal pra vocês - e as pessoas bebem e não se queixam" (ENTREVISTADA 08, 2019). 
Além de ter água de qualidade e quantidade suficiente para o consumo e as atividades do lar, um belo ato desenvolvido pela comunidade, foi a solidariedade em doar água para famílias que ainda não foram beneficiados pelo sistema.

\section{CONCLUSÕES}

As narrativas dos entrevistados demonstram que as tecnologias sociais implantadas na comunidade impactaram positivamente as famílias beneficiadas. Além de ter uma excelente aceitabilidade pela comunidade, os sistemas se mostraram eficientes e seguros. Conforto, autoestima, felicidade, saúde, qualidade de vida e independência, são alguns dos ganhos proporcionados pelos sistemas. As tecnologias são alternativas descentralizadas de baixo custo, fácil replicação que promovem acesso ao saneamento básico e água potável, indicando sua viabilidade de replicação em outras áreas e regiões com características similares.

\section{REFERÊNCIAS}

BARRAVIEIRA, B. Acidentes por serpentes dos gêneros bothrops lachesis e micrurus. Arq. Bras. Med., v. 65, n. 4, p. 345-355, 1991.

NEU, V.; DOS SANTOS, M. A. S.; MEYER, L. F. F. Banheiro ecológico ribeirinho: saneamento descentralizado para comunidades de várzea na Amazônia. Em Extensão, v. 15, n. 1, p. 28-44, 2016.

NEU, V.; GUEDES, V. M.; DA SILVA ARAÚJO, M. G.; MEYER, L. F. F.; BRITO, I. R.; BATISTA, L. M. Água da chuva para consumo humano: estudo de caso na Amazônia Oriental. Inclusão Social, v. 12, n. 1, 2018.

OLIVEIRA, H. F. A. D.; BARROS, R. M.; PASQUINO, J. A.; PEIXOTO, L. R.; SOUSA, J. A.; LEITE, R. D. S. Snakebite cases in the municipalities of the State of Paraíba, Brazil. Revista da Sociedade Brasileira de Medicina Tropical, v. 46, n. 5, p. 617-624, 2013.

WALDEZ, F.; VOGT, R. C. Aspectos ecológicos e epidemiológicos de acidentes ofídicos em comunidades ribeirinhas do baixo rio Purus, Amazonas, Brasil. Acta Amazonica, v. 39, n. 3, p. 681692, 2009. 